\title{
LA DIMENSIÓN PEDAGÓGICA DE LA INTERVENCIÓN DEL TRABAJO SOCIAL*
}

\author{
Claudia Bermúdez Peña**
}

\section{Resumen}

El artículo se propone avanzar en la reflexión en torno a la dimensión pedagógica del Trabajo Social. Se reconoce en el Trabajo Social un potencial pedagógico que no todas las veces es visible y en ese sentido se plantea la necesidad de visibilizarlo, asumiendo las teorías pedagógicas como orientadoras de la acción profesional.

Palabras clave: intervención social, Trabajo Social, pedagogía social, educación popular, educación no formal.

\section{Abstract}

The article proposes to advance the debate about the pedagogical dimension of Social Work. It is recognized in the Social Work potential teaching that not all times is visible and in that sense there is a need for more visible, assuming the pedagogical theories as the guide for professional action.

Key words: social Intervention, Social Work, social pedagogy, popular education, unreliable education.

* Artículo tipo 2: de Reflexión.

** Trabajadora Social, Magíster en Educación con énfasis en Educación Popular y Desarrollo Comunitario Docente de la Escuela de Trabajo Social y Desarrollo Humano de la Universidad del Valle.claubis311@yahoo.es 


\section{PRESENTACIÓN}

Este artículo retoma algunas elaboraciones que he desarrollado anteriormente y han sido publicadas ${ }^{1}$, e intenta avanzar alrededor del tema del lugar de lo pedagógico en la intervención social que se realiza desde el Trabajo Social.

¿Cuáles son las ideas y las teorías pedagógicas implícitas o explícitas en las modalidades educativas asumidas desde el Trabajo Social? ¿Cómo se plantean y realizan los aprendizajes, los procesos de formación, conceptos, apropiación de determinados contenidos en los sujetos, familias, grupos y/o comunidades en los procesos gestados desde el Trabajo Social? ¿Es el trabajo social una forma de educación? Son algunas de las preguntas que he pretendido abordar como orientadoras de la reflexión.

En este documento sostengo que en la medida que la intervención del Trabajo Social enfrenta una tensión que pasa por el encuentro de saberes desigualmente constituidos (Hleap, 2006); en que muchos de los proyectos sociales en los que se insertan trabajadores sociales actúan en el campo de lo simbólico - esto es en la organización de relaciones, en las representaciones sociales, en la reinterpretación de los problemas-(Martinic, 2005), y en la medida que tales programas poseen, construyen, resignifican y retoman dispositivos metodológicos de intervención, habría allí una dimensión pedagógica que no todas las veces es explícita y que sería necesario, entrar a considerar.

En primer lugar, presento una aproximación al tema de lo pedagógico, reconociendo que si bien sus mayores desarrollos se han situado desde el ámbito escolar, habría un campo emergente que reconoce cómo los procesos educativos trascienden ese ámbito. Posteriormente, con la idea de identificar la relación con el Trabajo Social rastreo los acercamientos que desde la profesión se ha tenido con la pedagogía, encontrando por un lado, que esa relación no todas las veces ha sido explícita y por el otro, que una posible vía de encuentro ha sido desde aquellas modalidades de educación

${ }^{1}$ Intervención social y Trabajo Social. Entre el deseo y el desencanto. Reflexiones pedagógicas desde el trabajo social. En: Revista colombiana de Trabajo Social. ISSN:0121-2818. No. 20, marzo de 2006.

- Educación Acción y Trabajo Social. En: Revista Prospectiva de la Escuela de Trabajo Social y Desarrollo Humano. Universidad del Valle. ISSN 0122-1213. No. 11 , octubre de 2006. 
que precisamente se sitúan por fuera del ámbito escolar. Se trata de La educación No formal, la Educación Popular y la Educación Social.

\section{1. ¿CÓMO APROXIMARSE A LO PEDAGÓGICO?}

En primer lugar, habría que plantear que adentrarse en el campo de la pedagogía, es adentrarse a un campo de múltiples interpretaciones. Diversos autores(Bruner,1997; Flórez, 1999), reconocen la condición de la pedagogía como ciencia en construcción, ello significa que abordar lo pedagógico de alguna manera implica situarse en un terreno de incertidumbre, reconocer que hay un abanico de opciones con múltiples puntos de partida y quizás con múltiples puntos de llegada, pues de alguna manera señala "el carácter lábil, viscoso y poroso, cambiante, multivariado de los procesos educativos en cada época histórica, en cada sociedad, en cada región" (Flórez, ibid.). Esta situación, hace que el abordaje de lo pedagógico implique en cierta medida dispersión y quizás en algunos momentos, confusión cuando situamos a la pedagogía frente a las denominadas ciencias de la educación.

Desde su especificidad, estas ciencias intentan acercarse al fenómeno de lo educativo y tratan de explicar los hechos de la educación. Tal es el caso de la sociología de la educación, la filosofía de la educación, la psicología de la educación entre otras. ¿Qué es lo que distingue entonces a la pedagogía de las otras ciencias de la educación?

Reconociéndose como parte de estas ciencias, la pedagogía se refiere a un "conjunto coherente de proposiciones que intentan describir, explicar en forma sistemática proceso educativos relacionados con la enseñanza y el aprendizaje humano". Entendida de esta manera, la pedagogía se refiere a una reflexión científica en torno a la educación, que construye y propone conocimientos alrededor de la enseñanza, el aprendizaje, las estrategias de enseñanza -instrucción-, las prácticas pedagógicas, el currículo, entre otras, teniendo como principio unificador su preocupación por la formación humana. 
Las teorías propiamente pedagógicas ${ }^{2}$, se han interesado por responder por lo menos a los siguientes interrogantes: a) ¿Cuál es la finalidad de la acción educativa? ¿Qué concepción de sujeto y de desarrollo se privilegia en la acción educativa? ¿Qué tipo de hombre y/o mujer interesa formar?; b) ¿Con qué métodos, técnicas y/o estrategias?; c) ¿Cuáles deben ser los contenidos? ¿Cómo y quién los selecciona?; d) ¿Quién debe impulsar el proceso formativo? y ¿qué tipo de relación se debe promover entre el educador y el educando?.

Responder a estos interrogantes, con la idea de orientar la acción educativa en procura de articular conceptos y prácticas - modelos pedagógicos ${ }^{3}$-, promover la incorporación de los marcos teóricos y su aplicación, así como tratar de explicar los significados de la acción educativa, también se constituyen en campo de estudio de la pedagogía.

Al revisar y acercarse a las teorías pedagógicas, no es difícil advertir que las mayores preocupaciones y quizás los mayores desarrollos sobre el hecho educativo desde la pedagogía se han dado mayoritariamente en el ámbito de la educación escolar. En menor medida, y acaso desde un terrenos aún más ambiguo emerge en su seno un conjunto de reflexiones que reconocen la existencia de procesos educativos en otros espacios que trascienden éste ámbito: el reconocimiento de otras educaciones (Trilla, 1993), la ya clásica distinción entre educación formal, educación informal y educación no formal (Coombs, 1975), la animación sociocultural, la recreación dirigida, la emergencia y consolidación de la pedagogía social en Europa e incluso la emergencia y consolidación de la Educación Popular Latinoamericana, así lo muestran. Por supuesto, que las reflexiones en torno al aprendizaje, la enseñanza y las estrategias en estos ámbitos no sólo se resignifican sino que plantea nuevos desafíos para la pedagogía.

Tal como puede observarse, lo pedagógico implica tanto una reflexión teórica alrededor del hecho educativo, como la puesta en escena de un

\footnotetext{
${ }^{2}$ Flórez (1999), distingue aquí la teoría pedagógica de la teoría sobre la enseñanza y el aprendizaje generada desde otras disciplinas, que han incorporado como parte de su objeto de estudio a la educación, "Aunque estas últimas puedan ocuparse eventualmente de fenómenos educativos o en aprendizaje, ello no las convierte automáticamente en una teoría pedagógica".

${ }^{3} \mathrm{El}$ modelo pedagógico es la representación de las relaciones que predominan en el acto de enseñar, es también un paradigma que puede coexistir con otros y que sirve para organizar la búsqueda de nuevos conocimientos en el campo de la pedagogía (Flórez, Rafael).
} 
conjunto de estrategias fundamentadas en dichas reflexiones ${ }^{4}$. Así mismo, la pedagogía se expresa en el hacer cotidiano y en la interacción de unos sujetos que se definen como educadores con unos sujetos que, en palabras de Freire, se definen como educandos. En cuanto la pedagogía promueve y orienta prácticas y acciones educativas, podría decirse que promueve una intervención sobre la sociedad teniendo como centro lo educativo. De alguna manera al poner el acento en la enseñanza, el aprendizaje y las estrategias del hecho educativo, su reflexión necesariamente se verá reflejada en una intervención. A este conjunto de intervenciones-acciones-, incluidas dentro del campo de la pedagogía, se le conoce como educación. La pedagogía en este orden de ideas, estudia la Educación. La educación se asume así como una práctica sistemática intencionada que la sociedad diseña para intervenir sobre sí misma, y cuya fundamentación está dada bajo orientaciones de teorías pedagógicas ${ }^{5}$.

En este orden, vale la pena preguntarse, ¿Cuáles son las ideas y las teorías pedagógicas implícitas o explícitas en las modalidades educativas asumidas desde el Trabajo Social? ¿Cómo se plantean y realizan los aprendizajes, los procesos de formación, conceptos, apropiación de determinados contenidos en los sujetos, familias, grupos y/o comunidades en los procesos gestados desde Trabajo Social? ¿Es el trabajo social una forma de educación?

\section{LO PEDAGÓGICO DESDE EL TRABAJO SOCIAL}

Para aproximarse al abordaje de estos interrogantes, es necesario adentrarse a la historia de la profesión y rastrear allí las relaciones o puentes que se han intentado establecer entre la pedagogía y el trabajo social.

${ }^{4}$ En este sentido lo pedagógico ni se limita exclusivamente al ámbito escolar, ni es el equivalente de lo metodológico de un proceso educativo, “... lo pedagógico no puede ser asumido, ni reducido, (...) únicamente como la "batería" de instrumentos metodológicos, que dan cuenta de un conjunto de técnicas y actividades que pueden ser tomadas indistinta y descontextualizadamente, lo pedagógico, tal como se señala, apunta a un tipo de reflexión más general que toca con la formación humana en sus distintas dimensiones" (Bermúdez, 2006).

${ }^{5} \mathrm{Si}$ bien no es objeto de reflexión en este artículo el tema de la educación, habría que señalar que para efectos del mismo se hace énfasis en su dimensión instrumental, es decir, entendiéndola como una acción pensada y planificada. No se asumirá aquí como actividad social general que la define como parte del proceso de socialización e integración de nuevos miembros a la sociedad y que por tanto está presente siempre que haya interacción humana. 
En primer lugar, habría que decir que en la historia de la profesión, pareciera que el Trabajo Social ha estado más ligado a la educación como actividad social general, que a lo pedagógico como reflexión global. En efecto, la manera como se ha hecho evidente ésta relación ha sido a través de tres modalidades de educación cuyo uso semántico ha sido indistinto, en muchas ocasiones cargado con poco contenido, no reflexionado y en ocasiones hasta homologados entre sí. Se trata de la Educación no formal, la Educación Social y la Educación Popular. Un elemento común a estas modalidades de educación, lo constituye el hecho que su acción se sitúa por fuera de lo escolar. No se encuentra en la historia de la profesión, más allá de esta relación con tales modalidades educativas y tangencialmente con la pedagogía social -principalmente en el trabajo social europeo-, una reflexión pedagógica sistemática que de cuenta de la manera como desde el trabajo social se conciben o se resignifican la enseñanza y el aprendizaje, las relaciones entre sujetos en interacción en contextos no escolares; por el contrario, quizás la mayor preocupación, que fue cuestionada precisamente por la reconceptualización pero que pese a ello persiste en la actualidad con algunos matices, se ha centrado en el tema de lo metodológico. Sin embargo, ni lo metodológico que ha sido central en la historia de la profesión ha sido pensado pedagógicamente, es decir, desde las teorías pedagógicas.

Por lo anterior, para intentar aproximarse a la dimensión pedagógica del Trabajo Social, habría que rastrear la relación del trabajo social con estas modalidades de educación.

\section{EDUCACIÓN NO FORMAL, EDUCACIÓN SOCIAL, EDUCACIÓN POPULAR Y TRABAJO SOCIAL}

En su definición clásica, Coombs y Ahmed (1975) educación formal, educación informal y educación no formal ${ }^{7}$. Es claro que

${ }^{6}$ Citado por Sarramona (1998).

${ }^{7}$ En la clasificación propuesta, los autores proponen la siguientes definiciones:

Educación formal: Es el sistema educativo, altamente institucionalizado, cronológicamente graduado y jerárquicamente estructurado que se extiende desde los primeros años de la escuela primaria hasta los últimos años de la universidad.

Educación informal: un proceso que dura toda la vida y en el que las personas adquieren y acumulan conocimiento, habilidades, actitudes y modos de discernimiento mediante las experiencias diarias y su relación con el medio ambiente. 
la acción de la educación no formal, se situaría en un marco institucional regulado, en algunos casos por agencias gubernamentales, agencias de cooperación internacional (FAO, UNESCO, UNICEF etc.), y en algunos momentos por instituciones de índole privado cuyo énfasis está puesto en lo que identifican como "capacitación para el trabajo". Un lugar clave de este marco institucional, lo constituye la producción y puesta en circulación de unas formas de nombrar -tanto a los problemas sociales como a los actores o población beneficiaria- $\mathrm{y}$ unas formas de operar.

La educación no formal toma fuerza con el paradigma del desarrollo en el mundo. En efecto, sus objetivos claramente definidos se inscribieron en promover el desarrollo de las áreas "atrasadas", "subdesarrolladas", en el "tercer mundo". Asumiendo el desarrollo como progreso, desde una definición económica y cuantitativa, y a los "pobres" no sólo como el blanco de los programas sociales sino como unos seres carentes y necesitados de intervención (Lander, 2003).

La Educación no formal se expresó de esta manera, como un conjunto de prácticas promovidas desde diversas agencias que definieron como eje de atención y beneficiarios a los pobres: “... Materializándose en un conjunto de prácticas, instituciones y estructuras, que han tenido un profundo impacto sobre el tercer mundo (...) los pobres se convirtieron en el blanco de prácticas más sofisticadas, de una variedad de programas que parecían ineludibles. Desde las nuevas instituciones de poder en los Estados Unidos y Europa; desde las oficinas del Banco Internacional para la Reconstrucción y Desarrollo y las Naciones Unidas; desde las universidades, institutos de investigaciones e instituciones de los Estados Unidos y Europa; desde las oficinas de planificación de las grandes capitales del mundo subdesarrollado este era el tipo de desarrollo que era activamente promovido" (Escobar, 2003, citado por Lander).

Es así, como desde la educación formal se crean una serie de dispositivos metodológicos que pretenden garantizar un control sobre la acción y sobre los cambios sociales. Esta acción, surge como producto de la interpretación particular de las condiciones de ciertos sectores poblacionales que como se

Educación no formal: toda actividad organizada, sistemática, educativa, realizada fuera del marco del sistema oficial, para facilitar determinadas clases de aprendizajes a subgrupos particulares de la población, tanto adultos como niños. 
ha dicho: son reconocidos como pobres. Tales dispositivos metodológicos se expresan en prácticas como la alfabetización funcional de adultos, la educación agrícola, la planificación familiar, la educación cooperativa, la educación nutricional, el desarrollo de la comunidad entre otros.

Hasta aquí, podemos notar que educación no formal obra como un tipo de intervención externa que no se pregunta en principio por el cómo es que los sujetos que se definen como destinatarios o beneficiarios, construyen su vida, su cotidianidad, ni cómo fundamentan sus deseos y aspiraciones, pero, sobre todo, no se pregunta por cuáles son los recursos con los que cuentan para transformar sus condiciones y si quieren transformarlas o no. Son leídos y asumidos como sujetos pasivos, y desde estas premisas se justifica la intervención. Es esta una mirada que niega el diálogo, homogeniza no sólo la manera de ver los beneficiarios sino, incluso, unas formas de obrar, que trata de imponer una visión del desarrollo. La planificación ha sido una de las herramientas centrales para lograrlo, con altas aspiraciones de volver previsibles los cambios en lo social.

Al parecer, y dado lo hasta aquí presentado, la educación no formal es una práctica que no cuenta con una reflexión pedagógica, pese a que se sitúa en el horizonte reflexivo de lo educativo, pues como lo señala Sarramona (ibíd.) “... un problema implicado en los programas no formales es el olvido de su propia naturaleza educativa. La escasa autonomía pedagógica de estos programas, y su nacimiento en órbitas tales como la económica-productiva o la política, ponen en segundo lugar el objetivo de la construcción del hombre en beneficio de la rentabilidad industrial”. Este lugar ha dado paso a que buena parte de las acciones desde la educación formal se sustenten desde el apoyo voluntario.

Adicionalmente, sería una práctica que está condicionada y subordinada a la convergencia de diversa variables que la harían posible o no: "La coordinación de las acciones de los "profesionales" de la educación no formal, la planificación de sus acciones y la reflexión pedagógica ulterior, están poco afirmadas en la práctica. Ello se debe a la menor sistematización de estas acciones; unas dependen de la iniciativa pública, muchas de las privadas, sus ciclos de desarrollo son cortos, las políticas inestables y frecuentemente incoherentes; las fuentes de financiación 
irregulares, las metas de los programas gozan de escasa autonomía pedagógica, los resultados quedan siempre bastante condicionados por las variables y circunstancias concretas del lugar donde se han aplicado los programas..." (ibíd.).

El Trabajo Social se inserta en la dinámica de la educación no formal a través de su presencia en los programas sociales, donde el trabajador social aparece como ejecutor de acciones en marcos definidos desde dichos programas.

En contraste, la educación social ${ }^{8}$ aparece como una praxis profesional, fundamentada científicamente por la pedagogía social. Ello significa que, desde la educación social, habría un claro interés en teorizar, conceptualizar, investigar e incluir todos los aspectos que reconozcan su cientificidad (Ortega, 1999). De esta manera, la educación social se define como: "aquella acción sistemática y fundamentada, de soporte, mediación y transferencia que favorece especificamente el desarrollo de la sociabilidad del sujeto a lo largo de toda su vida, circunstancias y contextos, promoviendo su autonomía, integración y participación crítica, constructiva y transformadora en el marco sociocultural que le envuelve" (Riera Romaní, J., 1998: 45).

"La educación social es o sería fundamental mente la dinamización o activación de las condiciones educativas de la cultura, de la vida social y de sus individuos y la compensación, normalización o en su caso, reeducación de la dificultad y el conflicto social, ... Promueve una sociedad que eduque

${ }^{8}$ La educación social corresponde a un tipo de práctica que surge en el contexto europeo, particularmente con los desarrollos de la Pedagogía Social en Alemania, donde tuvo una fuerte vinculación con el tema de la reconstrucción, a propósito de la posguerra (Ortega, 1999).

Para Algunos autores, la educación social -principalmente en España- tiene tres ámbitos claramente definidos:

- Animación sociocultural: Donde se incluyen principalmente programas que se ocupan de abordar el tema del ocio y el tiempo libre.

- Educación permanente y de adultos: entendida como aquella educación que se ocupa de temas como la educación compensatoria, de capacitación laboral, educación familiar, educación gerontológica entre otras.

- Educación social especializada: que incluye un campo de acciones donde el centro de abordaje son los menores en conflicto social, situaciones de desamparo, discapacidad, consumo de sustancias psicoactivas, delincuencia etc. Para una mayor ampliación acerca de este tema consultar: Ortega (1999) y Petrus (2000). 
y una educación que socialice, además de ayudar al educando a prevenir, compensar y reconducir la dificultad, la exclusión o el conflicto social en los grupos o los individuos (...) su función está en que ayude educando a evitar, equilibrar y reparar el riesgo, la dificultad o el conflicto social" (Ortega op.cit) (Subrayados míos)

Para algunos teóricos el lugar de lo institucional en la educación social es central, y concretamente lo es en el orden de lo gubernamental de la administración pública; en efecto, una de las funciones de la educación social sería obrar como mediadora en la tarea de acercar y procurar que los servicios gubernamentales lleguen finalmente a los destinatarios definidos para tal fin (Ortega, 1999, ibíd.). En ese orden de ideas la educación social define como población sujeto de acciones a los más desfavorecidos (Petrus, 2000 ibid) y en eso coincide con la educación no formal.

En términos generales, encontramos una fuerte aspiración de la educación social de ser previsible, y lograr el control del cambio social al igual que la educación no formal, de la misma manera, se sitúa como una intervención externa, con una forma particular de interpretar a los más desfavorecidos y sus problemas; pareciera que se obrara a nombre de las buenas intenciones sin indagar por la visión de los sujetos blanco de atenciones. Adicionalmente, encontramos en estas definiciones unos claros intereses en la reeducación, reincoporación donde pareciera que predomina una visión etnocéntrica, donde lo anómalo -entendido desde un solo punto de vista- no debe existir y la función de la educación social sería eliminarlo.

Variada literatura en el tema intenta vincular a la educación social con el trabajo social, aunque no logre profundizar al respecto. En ese sentido, algunos autores consideran que a pesar de no ser lo mismo, convergen y tienen claras coincidencias, (Caridge, 2000); para otros tienen un origen común en Europa, que posteriormente se tradujo en separación al identificar el tema de la asistencia social -desarrollado desde el trabajo social- con el social work norteamericano y al sentir- desde la pedagogía social- una mayor afinidad conceptual con la psicología social y la sociología (Ortega, ibíd.), y para otros, la educación social es la forma educativa del trabajo social "No concebimos un auténtico despliegue de los servicios sociales, un 
eficaz trabajo social que no sea educativo. Los estudios en intervenciones rigurosas de los trabajadores sociales deben asentarse en materiales, conceptuales y cientificos de carácter educativo y pedagógico" (Ortega, ibíd.).

Finalmente, tenemos a la educación popular que, en su expresión latinoamericana ${ }^{9}$, se inscribe como un tipo de práctica que tiene una clara intencionalidad de transformación social y compromiso político; como lo señala Mejía, la educación popular es una intervención intencionada con instrumentos dentro del mundo del saber y el conocimiento, que busca el empoderamiento de sujetos y grupos excluidos, segregados, desiguales, quienes, en el proceso, se constituyen en actores sociales que transforman su realidad en forma organizada (Mejía y Awad, 2003). Este sería un tipo de educación que no sólo se sitúa por fuera de lo escolar, sino que también llegó a oponerse a la escuela, en tanto ha sido interpretada como el lugar de reproducción y adoctrinamiento para la dominación ${ }^{10}$.

La educación popular pretende romper con los esquemas de incorporación y reeducación, lo que se propone es entender la realidad, establecer una relación dinámica entre acción y reflexión a partir del diálogo y de la negociación de saberes, es un tipo de educación que no pretende situarse al margen, como intervención externa, sino que pretende rescatar las voces de aquellos que los programas sociales reconocen como destinatarios y beneficiarios, allí se encuentra una concepción radicalmente opuesta tanto a la educación no forma ${ }^{11}$ como con la educación social. La educación popular se interesa además por el saber popular, antes que imponer su saber cree y valora profundamente la capacidad no sólo individual sino también colectiva para transformar condiciones sociales injustas y pretende romper con el esquema de pasividad de los sujetos; el punto de partida es una interpretación compartida, se preocupa por generar procesos políticos alternativos bajo la idea de lo participativo como centro. La educación popular, también, se preocupa por trabajar desde una didáctica

\footnotetext{
${ }^{9}$ Vale señalar que la expresión educación popular si bien en su más vasta difusión ha reconocido a Paulo Freire como su máximo exponente, tuvo algunos usos previos aunque con significados e intencionalidades diferentes a las planteadas a partir de este autor.

${ }^{10} \mathrm{Al}$ respecto ver Giroux, acerca de la pedagogía crítica o Illich, con la contraescuela.

${ }^{11}$ Aunque algunos autores en su afán de clasificar, han ubicado a la educación popular como una modalidad de educación no formal. (Ver Evans, 1981).
} 
particular que, en palabras de Freire, pretende romper el esquema bancario. En este orden, de ideas es claro que tras la educación popular hay una reflexión pedagógica explícita que se sitúa en el horizonte de la discusión de la pedagogía crítica. Adicionalmente, más que desde las agencias de cooperación internacional y de las agencias del orden gubernamental, la educación popular no necesariamente estaría sujeta a los programas y las políticas sociales aunque no sería mutuamente excluyente, desde el punto de vista del aporte que puede llegar a realizar este campo a este tipo de programas. La educación popular se preocupa más por atender, reconocer y promover las distintas organizaciones sociales que existen. "En cuanto en una práctica educativa conservadora se busca, al enseñar los contenidos, ocultar la razón de ser de un sinnúmero de problemas sociales; en una práctica educativa progresista, se procura, enseñar los contenidos, desocultar la razón de ser de aquellos problemas. Mientras la primera procura acomodar, adaptar a los educandos al mundo dado, la segunda busca inquietar a los educandos desafíndolos para que perciban que el mundo es un mundo dándose y que, por eso mismo, puede ser cambiado, transformado, reinventado" (Freire, 1993).

Desde el punto de vista del trabajo social latinoamericano, puede afirmarse que la educación popular ha permeado sus prácticas, principalmente a partir de la reconceptualización, momento desde el cual se han identificado unos fuertes vínculos entre ambas (Martínez y Agüero, 2003). Sin embargo, algunos colegas han hecho un uso instrumental de la educación popular al pretender encontrar en ella los elementos de la didáctica desligándose de la amplia reflexión que se propone. Otros en cambio, se han identificado tanto con la propuesta que se reconocen como educadores populares. Lo importante es que nuestra profesión comienza a reflexionar en torno a su labor educativa y concretamente al papel instrumental que ha venido desempeñando, interesándose además por procesos que generen transformación social más allá de las aspiraciones de previsibilidad institucional. 


\section{LA DIMENSIÓN PEDAGÓGICA DEL TRABAJO SOCIAL}

En este apartado me propongo visibilizar la dimensión pedagógica del Trabajo Social, pues tal como lo he venido señalando, es una dimensión que ha sido poco explorada, sin embargo, es fundamental para la intervención social que realiza el Trabajo Social.

Para Berstein (2000), desde el campo de la sociología de la educación, "Todas las experiencias conllevan un potencial pedagógico, pero no todas las experiencias son generadas pedagógicamente”. De esta manera, el autor, distingue dos modalidades de práctica pedagógicas: las visibles y las invisibles. Las prácticas pedagógicas visibles las define como “... una relación pedagógica progresiva en el tiempo y en la cual existe una intencionalidad poderosa para iniciar, modificar, desarrollar o cambiar el conocimiento, la conducta, o la práctica por alguien o algo que ya posee, o tiene acceso a recursos necesarios y a los medios de evaluación del aprendizaje", mientras las invisibles harían referencia a "...una relación pedagógica donde la iniciación, modificación, desarrollo o cambio del conocimiento, conducta o práctica ocurre, sin que ninguno de los miembros sea consciente de ello" (ibíd., subrayados míos). En otras palabras, mientras en las prácticas pedagógicas visibles subyacen principios como la jerarquía, las reglas y criterios $^{12}$ de manera explícita, en las prácticas pedagógicas invisibles, subyacen de manera implícitos.

Otros autores desde el campo de la pedagogía y específicamente referido al ámbito escolar, señalan la presencia de un currículo oculto, y definiéndolo como aquellos procesos que ocurren dentro de un espacio concreto -en ese caso, el aula-, valores y normas de las cuales no se acostumbra a hablar, pero cuya eficacia radica en que está presente más allá del contenido curricular. "Parte del convencimiento de que todo discurso educativo se basa en supuestos implícitos que a menudo el propio discurso ignora. Por ello el currículo oculto se revela sobretodo en las ausencias, las omisiones, las jerarquizaciones, las contradicciones y los desconocimientos "'13

\footnotetext{
${ }^{12}$ Los conceptos de jerarquía, reglas y criterios son ampliamente desarrollados en la teoría sobre la gramática de la transmisión cultural y social desarrollada por el autor.

${ }^{13}$ Para una mayor ampliación, ver Apple APPLE, M. W. (1986): Ideología y currículo. Madrid. Akal.
} 
En este orden de ideas, podríamos afirmar que, si bien desde el Trabajo Social no se ha planteado una reflexión abierta en torno a los procesos de enseñanza y aprendizaje que ocurren en las acciones que se agencia con individuos, familias, grupos y comunidades, es claro que si pretende incidir en ellos empleando diversas estrategias, que no necesariamente han sido pensadas pedagógicamente, en el sentido que hemos venido señalando: de estar acompañadas y orientadas por teorías pedagógicas. Desde este punto de vista, podríamos afirmar que el Trabajo Social desarrolla un tipo de práctica pedagógica invisible, en tanto todas sus acciones estarían cargadas de un potencial pedagógico.

Reconocer la dimensión pedagógica del Trabajo Social, significa reconocer dicho potencial, significa aceptar que es necesario pensar pedagógicamente las prácticas, esto es pasar de la pedagogía invisible a la pedagogía visible, lo que nos obliga a pensarnos en los procesos de formación que agenciamos, a preguntarnos por la intencionalidad, por lo oculto que subyace a nuestra prácticas, por la manera cómo se resignifica el aprendizaje, la enseñanza, las estrategias y las interacciones a la luz de los procesos sociales. Reconocer la dimensión pedagógica del Trabajo Social significa reconocer que no podemos asumirnos ni como educadores, ni asumir al Trabajo Social como una forma de educación mientras no asumamos lo pedagógico como orientador de nuestras prácticas.

De esta manera, pensar pedagógicamente nuestras prácticas lleva a plantearnos interrogantes como: ¿Cuál es la intencionalidad, o intencionalidades que se persiguen desde el trabajo social contemporáneo? ¿Qué tipo de relaciones promueve entre los diversos actores sociales presentes en la intervención? ¿Qué tipo de conocimientos y saberes se están generando desde la profesión? ¿Qué tipo de metodologías y didácticas se promueven, estimulan y se crean en el marco de la profesión?

Al respecto algunos autores (Hleap, 2006, Martinic, 2005) ofrecen pistas para avanzar en la comprensión y abordaje de estos interrogantes, aunque sus reflexiones no han sido generadas propiamente desde el Trabajo Social ${ }^{14}$. Desde sus aportes, se podría afirmar que la intervención social, y

${ }^{14}$ Tanto Hleap como Martinic plantean sus reflexiones desde la educación popular, sin embargo, encuentro potencial sus aportes en tanto se refieren a esos procesos educativos que se gestan por fuera de lo escoalr. 
para el caso que nos ocupa, la realizada desde el Trabajo Social, enfrenta una triple tensión desde el punto de vista de lo pedagógico. En primer lugar, la tensión, tiene que ver con las relaciones de poder y control que se expresan en el encuentro y relación de saberes diferentes y desigualmente constituidos (Hleap, 2006); en segundo lugar, una tensión que quizás emerge como consecuencia de la anterior, y que obra en el campo de lo simbólico; como lo señala Martinic (2005), los programas y proyectos sociales, obran en el campo de la representaciones y de la organización de la relaciones de los sectores poblacionales con los cuales se trabaja, en otras palabras, los proyectos de intervención se constituyen en un espacio en el que convergen un juego de interpretaciones acerca de los problemas sociales sobre los cuales se actúa, valiéndose de la implementación de dispositivos metodológicos. Y finalmente, la tensión relacionada con la emergencia de unas formas de re-interpretar y resignificar discursos y prácticas oficiales que sustentan la labor de las instituciones que adelantan proyectos sociales.

Desde el punto de vista del poder y control $^{15}$ que emerge como consecuenciadelencuentrodesaberesdistintos ydesigualmente, constituidos uno de los aspectos sobre los cuales debe reflexionar el Trabajo Social es sobre la puesta en escena del saber experto frente a los saberes sociales. Es claro, por ejemplo, que el saber experto por la vía de la especialización que se concreta en programas y proyectos sociales fragmenta la cotidianidad. En efecto, programas y proyectos focalizan su atención en un problema, dejan de lado otros de tal manera que la intervención social dada por la vía de dichos programas trae como consecuencia que dichos problemas sean atendidos diversamente, por instancias distintas, con recursos distintos. De esta manera, propuestas simultáneas, trabajando más o menos bajo los mismos principios se desarrollan con un mismo sector poblacional, que resulta siendo receptor de múltiples ofertas de atención.

Es así, como en la manera como se construye saber desde la intervención social del Trabajo Social habría que reflexionar sobre el control que se ejerce desde el saber experto y el lugar que en el proceso ocupan los saberes sociales, "La esfera de control social (...) denota los distintos mecanismos

\footnotetext{
${ }^{15}$ Buena parte de estas reflexiones las he tomado y adaptado de Cardarelli y Rossenfeld (2000).
} 
a través de los cuales los actores con mayor poder ejercen su influencia para legitimar y promover visiones, ideas proyectos y protagonismos sociales en las áreas de pobreza en el orden material y simbólico". De esta manera, "Los "saberes expertos" están en pugna con, o pasan por alto, los "saberes locales": los saberes expertos suelen permanecer seguros y atrapados en la centralidad condescendiente del discurso tecnocrático del "desarrollo"; los saberes locales operan clandestinamente, o naufragan, en las densas lógicas históricas del "lugar”. (Hleap, 2005, citado por Grosso)

La segunda tensión, sobre la cual debe reflexionar el Trabajo Social desde lo pedagógico, tiene que ver con lo simbólico. Tal como lo señala Martinic, las agencias ejecutoras, cuentan con sus propias maneras de nombrar, de nominar y desde criterios que consideran los más adecuados, entran a operar; así, “... gran parte de trabajo de las instituciones públicas $y$ de las organizaciones no gubernamentales que promueven proyectos sociales, intervienen en el campo simbólico actuando pedagógicamente en la organización de las relaciones y representaciones sociales de los grupos populares con los cuales trabajan. Se trata de experiencias que, por ejemplo, para solucionar problemas de producción de un campesino, prevenir enfermedades en la familia, cambiar pautas de crianza de los niños... promueven una relación pedagógica orientada a cuestionar y construir nuevas interpretaciones sobre dichos problemas..."

La tercera tensión, hace referencia a cómo desde esos mundos simbólicos de los actores ocurre un proceso de reproducción, resignificación y recontextualización del discurso (Díaz, 1999), para algunos autores, representa "la caja negra" de los programas y proyectos sociales.

En la medida que, existe un encuentro entre el saber local y el saber experto, y aunque el saber experto se imponga en los informes formales y en las políticas, el saber local se impone en la cotidianidad, ésta tensión ha sido poco explorada. De esta manera, esas formas de nombrar van creando un "pasaporte identitario" (Yudice, 2002) que les permite acceder a ciertos actores a algunos beneficios; reconocerse como madre cabeza de familia, joven en alto riesgo, desplazado por la violencia, afrodescendientes, o como los proyectos definan a sus beneficiarios, se convierte en un espacio de 
negociación donde no necesariamente entrar a hacer parte de los beneficios representa compartir la esfera discursiva oficial. "A los sujetos con menor poder relativo, les conviene identificarse con las argumentaciones del proyecto que los nomina, y con el lugar protagónico que ocupan en él, ya que esto los inscribe en una estructura dadora de sentido en un espacio recortado, particularmente en el contexto actual de desafiliación social" (Cardarelli y Rosendfeld, 2000).

Este aspecto, no debe despreciarse ni entenderse como una simple actitud oportunista de algunos, por el contrario debe considerarse como una de las esferas en las que ocurre la negociación y que debe hacerse visible.

En el contexto actual, bajo la idea de un estado acompañante "capacitador y fortalecedor", no responsable directo de las demandas sociales, los programas sociales operan como la presencia directa estatal, en ese sentido, la movilización per se resulta siendo innecesaria. "Así difícilmente pueden surgir identidades sociales fuertes, con capacidad para movilizar a otros actores significativos en torno a reformas institucionales y sociales más sustanciales" (Cardarelli y Rossenfeld: ibíd.). En este orden de ideas, se quiere producir sujetos manejables y tranquilos, gobernados a través de instituciones (Yudice, ibíd.).

\section{A MANERA DE CONCLUSIÓN}

Reconociendo el potencial pedagógico de la intervención del Trabajo Social, habría que decir que muchas de las acciones y experiencias promovidas desde el mismo, no son generadas pedagógicamente. En efecto, en la medida que tales acciones y experiencias no se apoyen en teorías pedagógicas y en la medida que no se reflexiona pedagógicamente el hacer, estaríamos frente al desarrollo de un conjunto de acciones que se sitúa en la esfera de la pedagogía invisible.

La dimensión pedagógica del Trabajo Social, por tanto, estaría dada por las reflexiones que se deben generar en torno al tipo de relaciones sociales que se establecen entre los distintos actores que se encuentran, el juego de saberes que se pone en escena, por el tipo de contenidos que se abordan, la manera como se definen y se nombran, por las intencionalidades implícitas 
y explícitas con las que se llega, en últimas, por trascender de la pedagogía invisible a una pedagogía visible.

Desde esta perspectiva, se reconoce que es necesaria una clara fundamentación pedagógica en la formación. Ello significa ampliar el espectro de los aportes de otras disciplinas a nuestra profesión y reconocer que además de la antropología, psicología, sociología y la historia, se requiere aproximarse de una manera más directa al campo pedagógico, conociendo las teorías pedagógicas y promoviendo reflexiones desde allí. Sólo de esa manera podríamos llegar a construir el rol del Trabajador Social como educador. Pues el Trabajo Social no es una forma de educación mientras no incorpore la reflexión pedagógica a su quehacer. 


\section{BIBLIOGRAFÍA}

BERSTEIN, Basil (2000). Hacia una sociología del discurso pedagógico. Cooperativa editorial magisterio. Colección seminarium. Bogotá.

BRUNER, Jerome (1997). Educación, puerta dela cultura. Editorial Visor. Bogotá.

CARDARELLLI, Graciela y ROSELNDFELD, Mónica (2000). Con Las mejores intenciones. Acerca de la relación entre el estado pedagógico y los agentes sociales. Ed. Paidós. Buenos Aires.

CARIDGE José Antonio (2005). Las fronteras de la pedagogía Social. Perspectiva científica e histórica. Gedisa editorial.

DÍAZ, Mario (1993). Aproximaciones al campo intelectual de la educación. Texto sin referencia.

DUQUE DAZA, Javier (1996). Algunas consideraciones acerca del quehacer del Trabajo Comunitario. Ponencia al seminario de Desarrollo Comunitario. Cartagena.

EVANS, David (1981). The planning of nonformal education. UNESCO, Paris.

FLOREZ, Rafael(1999). Evaluación Pedagógica y cognición. Teorías pedagógicas y prácticas educativas. Estudios de los modelos pedagógicos. McGraw-Hill, Bogotá.

FLOREZ, Rafael (1999). Hacia una pedagogía del conocimiento. McGraw-Hill, Bogotá.

FREIRE, Paulo (1970). Pedagogía del oprimido. Siglo XXI Editores, México.

FREIRE, Paulo (1993). Pedagogía de la esperanza. Siglo XXI Editores, Madrid.

HLEAP Borrero, José (2005). Violencia y Convivencia: Un Escenario Emergente de Educación Popular. Borrador para la discusión, inédito.

LANDER, Edgardo (2003). "Ciencias sociales, saberes coloniales y eurocéntricos". En: La colonialidad del saber. Eurocentrismo y ciencias sociales, perspectivas latinoamericanas. CLACSO, UNESCO. Buenos Aires.

MARTÍNEZ, Silvana, AGÜERO, Juan (2003). "La Educación Popular como instrumento metodológico en la formación profesional del Trabajador Social". En http://www.ts.ucr.ac.cr/reco-05.htm

MARTINIC, Sergio (2004). "La dimensión pedagógica de las políticas sociales. El aporte de la educación popular”. En: Revista la piragua, No. 21 CEAAL México.

MEJÍA, Marco Raúl, y AWAD, Ma. Inés (2002). La Educación Popular como campo del saber práctico. Educación Popular hoy en tiempos de globalización. Ediciones Aurora, Bogotá. 
ORTEGA, José Esteban (1997). Pedagogía Social. Ariel Educación, Barcelona. PETRUS, Antonio (2000). Los ámbitos de la educación social. Paidós, Barcelona.

SARRAMONA, Jaume y otros (1998). Educación No formal. Ariel Educación, Barcelona.

SUAREZ Salas, Virgilio (2008). El currículo oculto como estrategia académica. www.monografias.com/trabajos17/curriculum-oculto-estrategia/curriculumoculto-estrategia.shtml - 96.

TRILLA Bernet, Jaume (1993). Otras educaciones. Barcelona: Anthropos, Universidad Pedagógica nacional, México.

YUDICE, George (2002). El recurso de la cultura. Gedisa Editorial, Barcelona.

FECHA DE RECEPCIÓN: junio 27 de 2008

FECHA DE APROBACIÓN: septiembre 22 de 2008 